\title{
Agent as Detector: An Ecological Psychology Perspective on Learning by Perceiving-Acting Systems
}

\author{
Michael Young, Yi Guan, John Toman, Andy DePalma, Elena Znamenskaia \\ U-4, 249 Glenbrook Rd., Storrs, CT 06269-2004 \\ Tel: (860)-486-0182, Fax: (860) 486-0195 \\ Email: myoung@uconn.edu
}

\begin{abstract}
Ecological psychology has much to contribute as a theory of design for instructional and learning systems. With its roots in the psychology of James Gibson (1986), present day ecological psychology provides a unique understanding of how students think and learn, and further, how technology can enhance thinking and learning. This paper explores ecological psychology as a basis for design theory by describing five key ideas, then describing how they influenced four ongoing research projects concerning on-line log file analysis, collaborative learning, a reconceptualization of motivation, and teacher's naïve perceptions of curricular use of educational technology.
\end{abstract}

Keywords: learning theory, motivation, on-line assessment, teacher beliefs and practices.

\section{Five Key Ideas from Ecological Psychology}

At times our view of learning, from an ecological psychology perspective, has led us to make controversial statements designed to incite debate; such as "there is no memory" and "intelligence is not a property of individuals, but emerges from the interaction of agent with environment." These statements are indicative of our emphasis of perception over memory. Our statements arise from the use of a different metaphor for a thinking person-- people are sophisticated detectors of information. Contrast this with information-processing's favorite metaphor: people are sophisticated information processors (taking in, storing, and retrieving information). So instead of computers as the model for thinking, we would prefer to compare people to control systems like thermostats. Thermostats are simple signal detectors that can be tuned to detect different temperatures. People, we contend, are information detectors that can be tuned to detect different types of information... and the environment is full of useful information to be detected.

\section{Person as Detector - the Perceiving-Acting Cycle}

Our analysis assumes a perceiving-acting cycle that is the result of a working detector and presumes a system of agent-environment duals. It is this perceiving-acting cycle that allows for the coupling of individual and environment (Gibson, 1986), and for the development of a theory of cognition that does not require the inclusion of mediary variables. It involves an individual who detects (perceives) information (based on the constraints imposed by intentions) and acts, thereby transforming the environment so that new effectivity-affordance relationships can be perceived and acted upon.

\section{Intentional Dynamics and the Dynamics of Intentions}

Since our analysis rests fundamentally on dynamics, we must distinguish the types of dynamics that interest us. First, the dynamics of information within the environment are of critical interest. For example, Gibson's (1979/1986) notion of "invariance" (within an information field) across situations leads to an ecological psychological re-definition of information-processing psychology's concepts of "schema" and "scripts." But as complex systems, they can be driven to pursue multiple intentions simultaneously. So there are also "dynamics of intentions" (Kugler et al., 1992). That is, each learner has goals that change in priority as they interact with their environment.

\section{Co-Determined Interactions}

Key ideas from ecological psychology are often interpreted as stand alone properties (of the individual or of the environment), leading to the misapplication of information processing or behaviorist analyses to these ideas. Take for example the idea of "affordances" (Gibson, 1977). This idea has been explained elsewhere as the properties 
of the environment that permit certain activities (Greeno, 1994). But it is only the properties of the environment for a specific agent acting within space-time, not all agents or for all times. And an affordance is not an inherent property of the environment... only of its relationship to a specific agent, with specific goals and abilities (termed "effectivities").

\section{Learning as the Education of Attention and Intention}

Using the intentional spring as a metaphor (Shaw, Kadar, Sim, \& Repperger, 1992) we can state that learning by doing can be enhanced by guidance from a relative expert, working on a shared task, toward a shared Goal. This is much like what Lave and Wenger (1991) term legitimate peripheral participation. The task for designers, then, is to induce learners to have goals that relate to the curriculum, preferably authentic goals that specify the raison d'être of the materials (Young \& Barab, 1999).

\section{The Fascination with Automatic Performance}

Ecological psychology is fascinated with automatic (skilled) performance. From this perspective knowing is epistemic contact with one's world and depends not on rules, but on active perception (Shaw \& Turvey, 1995).

\section{Examples from Four Dissertation Studies}

\section{Example 1: Problem-Solving as On-Line Navigation}

Problem solving was described using Jason On-line from Jason XI through an analysis of on-line navigation as stored in log files. Mindful engagement was interpreted as the attention paid to critical aspects of the problem.

\section{Example 2: Motivation Patterns in Hypermedia Reading Comprehension}

Motivation was re-interpreted as a momentary on-the-fly assessment of the capacity of the current situation to afford progress toward an intended goal. Using reading comprehension from hypertext, participants continuously reported their "level of motivation" using a MIDI pedal. Results show that readers' level of motivation vary with the presence and absence of relevant problem-solving information.

\section{Example 3: Collaboration as Coordinated Perception-Action}

Collaboration was re-interpreted as the coordinated activity of an intentional system (in this case a design group). Using student engaged in a group PERL programming project, qualitative observations were interpreted within a framework where collaboration was characterized by having a shared goal, moving along a shared trajectory, and coordinating group perception-action.

\section{Example 4: Misconceptions: Teachers' Naïve Perceptions of Educational Technology}

Teacher misconceptions about the curricular use of educational technology were re-interpreted as novice perceptions, not yet tuned to detect many affordances of (in this case) educational technology.

\section{References}

Gibson, J. J. (1986) The ecological approach to visual perception. Hillsdale, NJ: Erlbaum.

Greeno, J. G. (1994). Gibson's affordances. Psychological Review, 101(2), 236-342.

Kugler, P. N., Shaw, R. E., Vicente, K. J., Kinsella-Shaw, J. M. (1992). Inquiry into intentional systems I: Issues in ecological physics. Psychological Research, 52, 98-121.

Lave, J. \& Wenger (1990). Situated Learning: Legitimate Periferal Practice. New York: Cambridge U. Press.

Shaw, R. E., Kadar, E., Sim, M. \& Repperger, D. W. (1992). The intentional spring: A strategy for modeling systems that learn to perform intentional acts. J. of Motor Behavior 24(1), 3-28.

Young, M. F., \& Barab, S. (1999). Perception of the raison d'etre in anchored instruction: An ecological psychology perspective. Journal of Educational Computing Research, 20(2), 113-135. 